\title{
Erratum: BrainFD: Measuring the Intracranial Brain Volume With Fractal Dimension
}

\author{
Frontiers Production Office* \\ Frontiers Media SA, Lausanne, Switzerland
}

Keywords: aging, biomarkers, fractal dimension, intracranial brain volume, MRI, neuroinformatics, OASIS brain database, VoxelMorph

\section{OPEN ACCESS}

Approved by:

Frontiers Editorial Office,

Frontiers Media SA, Switzerland

*Correspondence:

Frontiers Production Office production.office@frontiersin.org

Received: 11 January 2022

Accepted: 11 January 2022

Published: 04 February 2022

Citation:

Frontiers Production Office (2022)

Erratum: BrainFD: Measuring the Intracranial Brain Volume With Fractal

Dimension.

Front. Aging Neurosci. 14:852590.

doi: 10.3389/fnagi.2022.852590

\section{An Erratum on}

BrainFD: Measuring the Intracranial Brain Volume With Fractal Dimension by Ashraf, G. M., Chatzichronis, S., Alexiou, A., Kyriakopoulos, N., Alghamdi, B. S. A., Tayeb, H. O., Alghamdi, J. S., Khan, W., Jalal, M. B., and Atta, H. M. (2021). Front. Aging Neurosci. 13:765185. doi: 10.3389/fnagi.2021.765185

Due to a production error, the reference for "Soltanifar, 2021" was incorrectly written as "Soltanifar, M. (2021). A generalization of the hausdorff dimension theorem for fractals. Mathematics 9:1546. doi: 10.1103/PhysRevE.85.056314". It should be "Soltanifar, M. (2021). A generalization of the hausdorff dimension theorem for deterministic fractals. Mathematics 9:1546. doi: 10.3390/math9131546".

The publisher apologizes for this mistake. The original version of this article has been updated.

Copyright $(2022$ Frontiers Production Office. This is an open-access article distributed under the terms of the Creative Commons Attribution License (CC BY). The use, distribution or reproduction in other forums is permitted, provided the original author(s) and the copyright owner(s) are credited and that the original publication in this journal is cited, in accordance with accepted academic practice. No use, distribution or reproduction is permitted which does not comply with these terms. 